Check for updates

Cite this: RSC Adv., 2019, 9, 19104

\title{
Impact of hydrothermal pre-treatment on the anaerobic digestion of different solid-liquid ratio sludges and kinetic analysis
}

\author{
Lei Gong, Xiaoqi Yang, Zaizhao Wang, Jun Zhou D * and Xiaogang You
}

This study is an assessment of hydrothermal pre-treatment (HTP) of different solid-liquid ratio (SLR) sewage sludge for enhancement of biogas production by anaerobic digestion. Anaerobic digestion efficacy was investigated by biochemical methane potential (BMP) tests and kinetic analyses. The results indicated that the solid-liquid ratio (SLR) of sludge could influence the COD solubilization and the concentration of volatile fatty acids (VFAs) after HTP. BMP tests revealed that HTP could improve the final methane yield. For the different solid-liquid ratios $(5 \%, 8 \%, 10 \%, 12 \%$ and $15 \%)$ of sludge after HTP, the methane contents were found to be $64 \%, 66 \%, 62 \%, 61 \%$ and $60 \%$, respectively. The optimum solid-liquid ratio was found to be $8 \%$, and its cumulative biogas yield was $425.57 \mathrm{~N} \mathrm{ml} \mathrm{g}^{-1}$ VS. The modified Gompertz model and Logistic model were used for kinetic study of biogas production. Kinetic study results showed that the experimental data could be fitted with the two models and the modified Gompertz model was better fitted with the experimental data than the Logistic model. These findings proved that choosing an appropriate solid-liquid ratio for HTP could effectively improve the anaerobic digestion process of sewage sludge.

Received 5th March 2019

Accepted 9th June 2019

DOI: $10.1039 / \mathrm{c} 9 \mathrm{ra01662g}$

rsc.li/rsc-advances

technologies can be used to improve the hydrolysis step of anaerobic digestion. Methane production, dewaterability, solid reduction, and pathogen removal can be enhanced for using different pre-treatment technologies. ${ }^{12,13}$

In order to enhance the performance of anaerobic digestion, several pre-treatment technologies have been considered to increase the physicochemical characteristics of sewage sludge. Various methods were investigated by many researchers, such as biological pre-treatment, ${ }^{14}$ physical (ultrasonic, microwave et al.) pre-treatment, ${ }^{15-17}$ chemical (ozone oxidation, thermal and hydrolysis et al.) pre-treatment. ${ }^{12,18-20}$ Such sludge pretreatment technologies are working on the principle of disintegration of cell walls and causing lysis, leading to the release of intracellular organic matter that become more easy to be used for anaerobic microorganisms. Among thermo-chemical pretreatment methods, hydrothermal pre-treatment (HTP) has significant enhancement effect on achieving organic material degradation and anaerobic digestion performance. ${ }^{21}$ HTP is under high temperature and pressure to achieve the cell solubilization and destruction of sewage sludge efficiently. ${ }^{22}$ Many researchers have been studied the influence on solid-liquid ratio (SLR), ${ }^{23}$ temperature and time for HTP of sludge, ${ }^{24-26}$ applied temperature range from $100{ }^{\circ} \mathrm{C}$ to $280^{\circ} \mathrm{C}$ for fifteen minutes to several hours..$^{27,28}$ They also proved that HTP was an effective method to increase methane production and reduced volatile solids (VS), with a relatively low energy input and being a more environmentally technology.

College of Environmental and Safety Engineering, Qingdao University of Science and Technology, 53, Zhengzhou Road, Qingdao, Shandong Province 266042, China. E-mail: zj1982leva@163.com 
In previous work, hydrothermal temperature and time had been proved to have influence on anaerobic digestion, ${ }^{29}$ it found the optimal pre-treatment temperature and time was $160{ }^{\circ} \mathrm{C}$ for $60 \mathrm{~min}$. Also there were few studies mentioned the relationship of different solid-liquid ratio (SLR) and biogas production. The SLR was related to moisture content of sludge after dewatering and the cost of sludge conditioning. This study was to use hydrothermal pre-treatment on different SLR sludge, discussed the sludge characteristics and anaerobic biodegradability. It was not obvious if a small gradient of SLR was used. So in this study set five groups of $5 \%, 8 \%, 10 \%, 12 \%$ and $15 \%$. Biogas yield and methane content were obtained in the anaerobic biodegradability tests and the kinetic study was analyzed by the modified Gompertz model and Logistic model. The purpose of this experiment was to find the best solid-liquid ratio and provided the basis for industrial application.

\section{Materials and methods}

\subsection{Sewage sludge characteristics}

The sewage sludge sample was taken from the discharge of a horizontal spiral filter centrifuge in a municipal wastewater treatment plant in Qingdao, China. Primary characteristics of different SLR sludge (such as total solid content (TS), volatile solid content (VS), total COD (TCOD), soluble COD (SCOD), ammonia nitrogen $\left.\left(\mathrm{NH}_{4}-\mathrm{N}\right)\right)$ were listed in Table 1 . After that, the sewage sludge was stored at $4{ }^{\circ} \mathrm{C}$ to minimize impact of biological activity. Each experiment was repeated three times and a mean value was used in the study.

In the experiment, the SLR of the sludge was determined by

$$
\mathrm{SLR}=\frac{m \times(1-\mathrm{MC})}{m \times \mathrm{MC}+W} \times 100 \%
$$

While, $m$ is the quantity of the sludge; MC is the sludge moisture content; $W$ is the volume of distilled water.

\subsection{Hydrothermal pre-treatment experiments}

HTP experiments were performed using a $2000 \mathrm{ml}$ lab-scale reactor. The reactor (Fig. 1) included a reactor body, heater, attemperator, and stirrer et al. For all experiments, a $1200 \mathrm{ml}$ feedstock (sludge and water mixture) was loaded into the reactor. The experiment operating temperature was $160{ }^{\circ} \mathrm{C}$, the pressure of HTP was $0.8 \mathrm{MPa}$, and the reaction time was $60 \mathrm{~min}$. The samples in the reactor were mixed using an agitator stirring at $220 \mathrm{rpm}$. The steam was discharged from the pressure reducing valve and the sludge was removed after the completion of hydrothermal pre-treatment reaction.

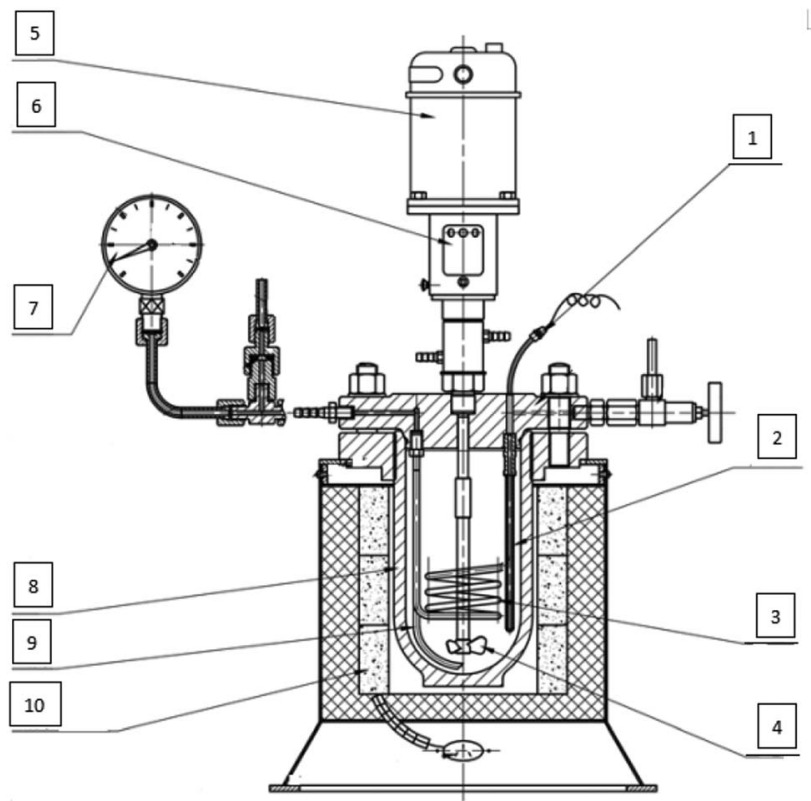

Fig. 1 The reactor of hydrothermal pre-treatment reaction. (1) Temperature measuring element. (2) Temperature measuring casing. (3) Cooling coil. (4) Stirring paddle. (5) Motor. (6) Magnetic drive system. (7) Pressure gage. (8) Reactor body. (9) Sampling tube. (10) Electric heating system.

\subsection{Anaerobic biodegradability batch tests}

Each sample from HTP and the raw sludge were performed by biochemical methane potential (BMP) tests. BMP tests for the experiments had also been performed in triplicate to guarantee the objectivity of the observed results. Each experiments inoculated with the active anaerobic sludge from the Qingdao sewage treatment plants in China and the inoculum was domesticated under $35{ }^{\circ} \mathrm{C}$ for 7 days before the BMP tests. When no significant gas production was observed, the inoculum was ready to be used. BMP tests were performed by the Bioprocess Control (Endeavor, Sweden $\mathrm{AB})$. The Bioprocess Control consisted of an anaerobic digestion device, a biogas metering device, an attemperator, and ENDEAVOUR software. Anaerobic digestion device contained five sealed bottles of $2300 \mathrm{ml}$, each bottle had a rotating shaft for mixing and the operating temperature controlled by electro-thermostatic water cabinet was $35{ }^{\circ} \mathrm{C}$. Biogas produced by the samples could be measured by the gas flowmeter. The ratio of inoculum VS to substrate VS was set at 1.5 according to the previous studies. ${ }^{30,31}$ After the mixture was added, the bottles were flushed with $\mathrm{N}_{2}$ to remove $\mathrm{O}_{2}$. The blank digester containing only inoculum and untreated sludge was operated simultaneously with other digestion

Table 1 Characteristics of the different SLR sludge

\begin{tabular}{|c|c|c|c|c|c|}
\hline Parameters & $5 \%$ & $8 \%$ & $10 \%$ & $12 \%$ & $15 \%$ \\
\hline VS (\%) & $1.93 \pm 0.013 \%$ & $4.03 \pm 0.05 \%$ & $5.32 \pm 0.017 \%$ & $6.43 \pm 0.022 \%$ & $7.72 \pm 0.06 \%$ \\
\hline TS (\%) & $3.44 \pm 0.05 \%$ & $7.64 \pm 0.052 \%$ & $9.99 \pm 0.036 \%$ & $12.34 \pm 0.04 \%$ & $14.33 \pm 0.055 \%$ \\
\hline $\operatorname{SCOD}\left(\mathrm{mg} \mathrm{L}^{-1}\right)$ & $8750 \pm 47.13$ & $15578 \pm 128.64$ & $24375 \pm 327.29$ & $26897 \pm 319.38$ & $29375 \pm 309.96$ \\
\hline TCOD $\left(\mathrm{mg} \mathrm{L}^{-1}\right)$ & $30625 \pm 591.76$ & $62125 \pm 316.56$ & $96250 \pm 345.06$ & $107659 \pm 376.93$ & $113750 \pm 384.7$ \\
\hline $\mathrm{NH}_{4}-\mathrm{N}\left(\mathrm{mg} \mathrm{L}^{-1}\right)$ & $794 \pm 8.544$ & $1094 \pm 13.45$ & $1593 \pm 8.54$ & $1802 \pm 14.73$ & $2164 \pm 14.8$ \\
\hline
\end{tabular}


experiments. Daily biogas production and cumulative biogas production were recorded by the ENDEAVOUR software.

The methane content of the biogas was analyzed by the gas chromatography (GC-1100, Pease Corporation, China). A volume of $0.5 \mathrm{ml}$ of biogas was injected into the gas chromatography to measure biogas composition, detected proportions of methane and carbon dioxide. The temperatures of injector, detector and column were set $100{ }^{\circ} \mathrm{C}, 150^{\circ} \mathrm{C}$, and $120^{\circ} \mathrm{C}$, respectively. The gas composition was measured every two days. Digestion experiment was conducted until biogas production ceased.

\subsection{Other analytical methods}

The physical and chemical parameters VS, TS, total nitrogen (TN), $\mathrm{NH}_{4}-\mathrm{N}$, and COD were determined according to standard methods (Ministry of Environmental Protection, China (MEP), 2002). The SCOD was measured after centrifuging at $3000 \mathrm{rpm}$ for $20 \mathrm{~min}$ and filtering the supernatant through membranes with mesh size of $0.45 \mu \mathrm{m}$. TNM and $\mathrm{NH}_{4}-\mathrm{NM}$ were the total nitrogen and ammonia nitrogen analyzed from the mixed liquor. $\mathrm{TN}$ and $\mathrm{NH}_{4}-\mathrm{N}$ were extraction from centrifuged the supernatant. The TCOD parameters were obtained from the mixed liquor. Volatile fatty acids (VFA) were analyzed using Pease gas chromatograph equipped with a flame ionization detector (FID) and a KB-FFAP column $(30 \mathrm{~m} \times 0.25 \mathrm{~mm} \times 0.50$ $\mu \mathrm{m})$. Operating conditions were injector temperature $230{ }^{\circ} \mathrm{C}$, FID temperature $230{ }^{\circ} \mathrm{C}$, oven temperature program: $70-180{ }^{\circ} \mathrm{C}$ $\left(20{ }^{\circ} \mathrm{C} \mathrm{min}^{-1}\right)$, held for $5 \mathrm{~min}$. Nitrogen was used as a carried gas. The VFAs were detected include acetic acid, propionic acid and butyric acid. The other acids such as lactic and valeric were very low, which had a little effect on the experimental results. The total VFAs was the sum of the three acids.

VS reduction (VSR) rate was determined by (2-2). ${ }^{32}$

$$
\mathrm{VSR}=\frac{\mathrm{VS}_{0} / \mathrm{TS}_{0}-\mathrm{VS}_{1} / \mathrm{TS}_{1}}{\mathrm{VS}_{0} / \mathrm{TS}_{0}-\left(\mathrm{VS}_{0} / \mathrm{TS}_{0} \times \mathrm{VS}_{1} / \mathrm{TS}_{1}\right)} \times 100 \%
$$

While, $\mathrm{VS}_{0} / \mathrm{TS}_{0}$ is the VS/TS before the BMP tests, and $\mathrm{VS}_{1} / \mathrm{TS}_{1}$ is the VS/TS after the BMP tests.

Solubilization COD was determined by the formula (2-3). ${ }^{33}$

$$
\text { Solubilization COD }=\frac{\mathrm{SCOD}_{\mathrm{T}}-\mathrm{SCOD}_{0}}{\mathrm{TCOD}_{0}-\mathrm{SCOD}_{0}} \times 100 \%
$$

While, $\mathrm{SCOD}_{0}$ and $\mathrm{TCOD}_{0}$ are the initial SCOD and TCOD of different SLR sludge, and $\mathrm{SCOD}_{\mathrm{T}}$ is the SCOD of different SLR sludge after HTP.

The different SLR sludge of $\mathrm{TN}$ and $\mathrm{NH}_{4}-\mathrm{N}$ solubilization were determined by the formula (2-4).

$$
\text { Solubilization }=\frac{A_{\mathrm{T}}-A_{0}}{B_{0}-A_{0}} \times 100 \%
$$

While, $A_{0}$ and $B_{0}$ are the initial TN $\left(\mathrm{NH}_{4}-\mathrm{N}\right)$ and TNM $\left(\mathrm{NH}_{4}-\mathrm{NM}\right)$ of different SLR sludge, and $A_{\mathrm{T}}$ is the TN $\left(\mathrm{NH}_{4}-\mathrm{N}\right)$ of different SLR sludge after HTP.

\subsection{Kinetic analysis}

Kinetic analysis was used two kinetic models: the modified Gompertz model and the Logistic model. With the two models, the maximum biogas production rate, biogas production potential of the substrate and the lag phase of their action could be determined with available experimental results. The experimental results obtained from all samples were fitted with the two kinetic models. And the two kinetic models described cumulative biogas production from batch digesters, assuming that biogas production was a function of bacterial growth. ${ }^{34,35}$ The models expression was given by. ${ }^{36}$

$$
\begin{gathered}
P(t)=P \exp \left\{-\exp \left[\frac{2.718 \times R_{\mathrm{m}}}{P} \times(\lambda-t)+1\right]\right\} \\
P(t)=\frac{P}{1+\exp \left[4 R_{\mathrm{m}} \times \frac{\lambda-t}{P}+2\right]}
\end{gathered}
$$

While, $P(t)$ is cumulative biogas production; $P$ is biogas production potential; $R_{\mathrm{m}}$ is maximum biogas production rate; $\lambda$ is lag time.

In order to evaluate the models, the kinetic parameters of the samples were calculated using final prediction error (FPE), ${ }^{37}$ correlation of determination $\left(r^{2}\right)^{38}$ and root mean square error $(\mathrm{RMSE})^{39}$ for this analysis.

$$
\begin{gathered}
R=\frac{\sum_{i=1}^{n}\left(z_{i}-\bar{z}\right)\left(w_{i}-\bar{w}\right)}{\sqrt{\sum_{i=1}^{n}\left(z_{i}-\bar{z}\right)^{2} \sum_{i=1}^{n}\left(w_{i}-\bar{w}\right)^{2}}} \\
r^{2}=R \\
\operatorname{RMSE}=\sqrt[2]{\frac{1}{n} \sum_{i=1}^{n}\left(z_{i}-w_{i}\right)^{2}}
\end{gathered}
$$

$$
\mathrm{FPE}=\frac{1+p / n}{1-p / n} \times \frac{1}{n} \times \sum_{i=1}^{n} \frac{1}{2}\left(\frac{z_{i}-w_{i}}{z_{i}}\right)^{2}
$$

While, $z_{i}$ is the experimental value; $w_{i}$ is the predicted value; $n$ is the number of samples. $P$ is the degree of freedom.

\section{Results and discussion}

\subsection{Effect of HTP on different SLR sludge solubilization}

3.1.1 COD solubilization. Compared with the raw sludge for different SLR, the SCOD was improved by $282.15 \%$, $309.95 \%, 279.49 \%, 239.23 \%$ and $180.85 \%$ for SLR 5\%, 8\%, 10\%, $12 \%$ and $15 \%$, respectively, after HTP. The physicochemical property of the sludge was found to be improved and the concentrations of SCOD was enhanced after HTP. ${ }^{40}$ Results from this study also indicated that the SLR significantly affected the SCOD of the sludge, and showed the maximum increment at the SLR 8\%. The SCOD of different SLR in raw sludge, after HTP and solubilization COD were shown in Fig. 2.

HTP as a pre-treatment technique could destroy the sludge floc structure and cell wall, improved the dissolution of organic matter in the sludge. ${ }^{25}$ In this study, the solubilization COD were $95.41 \%$, 96.09\%, 94.78\%, 89.67\% and 62.96\% for SLR 5\%, 


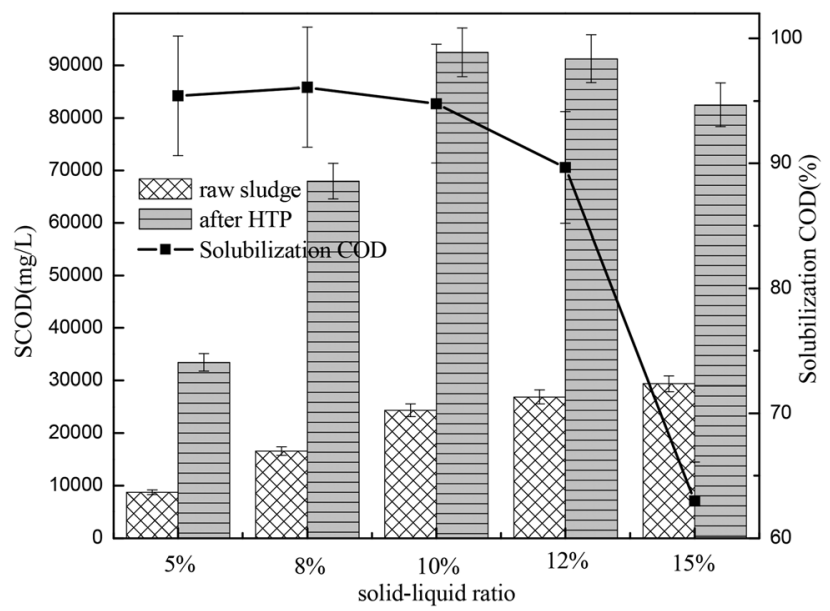

Fig. 2 SCOD of different SLR raw sludge, after HTP and solubilization COD.

$8 \%, 10 \%, 12 \%$ and $15 \%$, respectively. From the SLR $8 \%$ to $15 \%$, the solubilization COD were decreased as the SLR increased. Seong et $a l^{41}$ evaluated the COD solubilization for different TS concentrations under temperatures ranging from 100 to $220^{\circ} \mathrm{C}$. As TS concentration increased, the solubilization decreased gradually at $160{ }^{\circ} \mathrm{C}$, which was consisted with our conclusion.

But when the SLR was 5\%, the solubilization COD was lower than the SLR 8\%. Viscosity was an important parameter which could affect the solubilization and biodegradability of sludge. The viscosity decreased with the SLR decreased. ${ }^{42}$ On the other hand, when under the high temperature and pressure, the viscosity also decreased. ${ }^{12}$ Therefore, the SLR 5\%, led to more organic substances degraded or volatilized due to the lower viscosity, resulting in the decrease of the solubilization COD.

VS/TS were found to improve by $3.21 \%, 4.08,2.10 \%$ and $1.89 \%$ for SLR $5 \%, 8 \%, 10 \%$ and $12 \%$ compared with the raw sludge, but the SLR 15\% was further shown to decrease by $2.56 \%$. It was probably that the organic matters including VS were pyrolyzed at $160{ }^{\circ} \mathrm{C},{ }^{43}$ the more solid in sludge, the more escape of $\mathrm{CO}_{2}$ for the organic compounds which reduced the volatile matters.

3.1.2 VFAs solubilization. In the process of anaerobic digestion, VFAs are important intermediate product of which methanogens mainly use to produce methane. ${ }^{44}$ The concentrations of VFAs in the samples were shown in Table 2. Compared with the raw sludge, the concentrations of VFAs were improved by $49.81 \%, 58.78 \%, 26.92 \%, 38.44 \%$, and $45.75 \%$ for SLR $5 \%, 8 \%, 10 \%, 12 \%$ and $15 \%$, respectively. It could be observed that HTP had an important effect on VFAs production. During HTP, long chain fatty acids could be degraded to low chain fatty acids. Wilson reported that the amino acids decomposed to VFAs above $160{ }^{\circ} \mathrm{C} .{ }^{45}$ Moreover, the increment of VFAs were also influenced by the SLR, and the optimum SLR was $8 \%$. It indicated that the low SLR were more effective at promoting the dissolution of long-chain organic acids. In addition, after HTP, the concentrations of acetic acids and butyric acids had a significantly increase compared with the raw sludge, since they were the degradation products of several

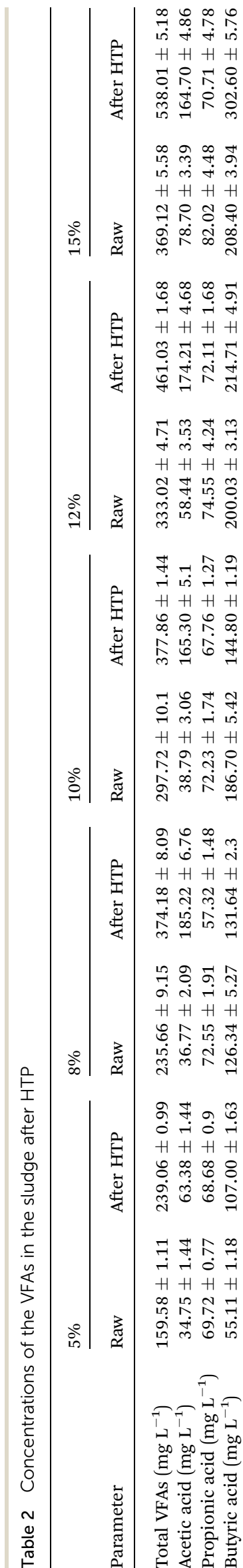


organic matters. Li et al. also considered an increase of VFAs were due to the degradation of lipids. ${ }^{46}$

3.1.3 Nitrogen solubilization. Total nitrogen and ammonia nitrogen are important parameters, because they can inhibit the anaerobic digestion when above certain levels. ${ }^{47}$ Table 3 showed the concentrations of $\mathrm{TN}$ and $\mathrm{NH}_{4}-\mathrm{N}$ for different SLR of sludge.

After hydrothermal pretreatment (HTP), the $\mathrm{NH}_{4}-\mathrm{N}$ solubilization were improved by $103.12 \%, 110.44 \%$, 97.54\%, 90.23\%, and $101.37 \%$ for SLR 5\%, 8\%, 10\%, $12 \%$ and 15\%, respectively. Wilson and Novak ${ }^{\mathbf{4 5}}$ demonstrated that the proteins existing as particulate matter could be converted into $\mathrm{NH}_{4}{ }^{+}-\mathrm{N}$ through hydrothermal pretreatment, so the $\mathrm{NH}_{4}-\mathrm{N}$ solubilization in all the samples increased. The trend of $\mathrm{TN}$ solubilization was similar to the $\mathrm{NH}_{4}-\mathrm{N}$. After HTP, the TN solubilization were improved by $102.16 \%, 107.54 \%, 60.04 \%$, 77.43\%, and $100.86 \%$ for SLR $5 \%, 8 \%, 10 \%, 12 \%$ and $15 \%$, respectively. They both had the highest solubilization at the SLR $8 \%$. It was probably because the lower SLR, the easier dissolution of nitrogen. In contrast, due to the minimum concentration of sludge for the SLR 5\%, the nitrogen rapidly dissolved, and exposed under the high temperature and pressure for a longer time. ${ }^{45}$ Hence, the $\mathrm{NH}_{4}-\mathrm{N}$ and $\mathrm{TN}$ further volatilized and degraded.

\subsection{Effect of HTP on different SLR sludge anaerobic digestion}

3.2.1 Daily biogas production and methane content. The daily biogas production and methane content datas were presented in Fig. 3 and 4.

Fig. 3 showed the results of the daily biogas production in anaerobic digestion within 40 days. There were three remarkable peaks during anaerobic digestion for all the samples. The first peak of the daily biogas production were found to be 16.80 , 42.50, 55.13, 22.27, 20.21 and $18.77 \mathrm{~N} \mathrm{ml} \mathrm{g}^{-1}$ VS for raw sludge, SLR 5\%, $8 \%, 10 \%, 12 \%$ and 15\%, respectively. For the different SLR, the first and second peak occurred earlier and the daily biogas production was higher compared with the raw sludge, which was due to the small particle size was benefit for degradation under the high temperature and pressure. ${ }^{48}$ In contrast, the third peak was delayed compared with the raw sludge, it might be that the refractory organic matter had been effectively degraded for the raw sludge, but there were lots of refractory organic matter for the different SLR, thereby slow down the anaerobic digestion.

Following the BMP test, methane content was shown in Fig. 4. The methane content had a rising trend in the beginning, it was due to the decomposition of acetic acid. ${ }^{49}$ The time reached on the first peak delayed for the raw sludge, it was because the refractory organic matter was difficult to dissolve, thus made the process slower than the others. ${ }^{50}$ In the late stage of anaerobic digestion, the methane content was essentially stable in the range of 52-64\%. It indicated that the composition of biogas contained around 50-70\% methane, 20-30\% carbon dioxide and less nitrogen and hydrogen sulphide gas. ${ }^{51}$ Overall, after HTP, the methane contents were found to be higher than the raw sludge, which indicated that HTP had an effective effect on the sludge properties. ${ }^{52}$ Also, the SLR 8\% had the highest

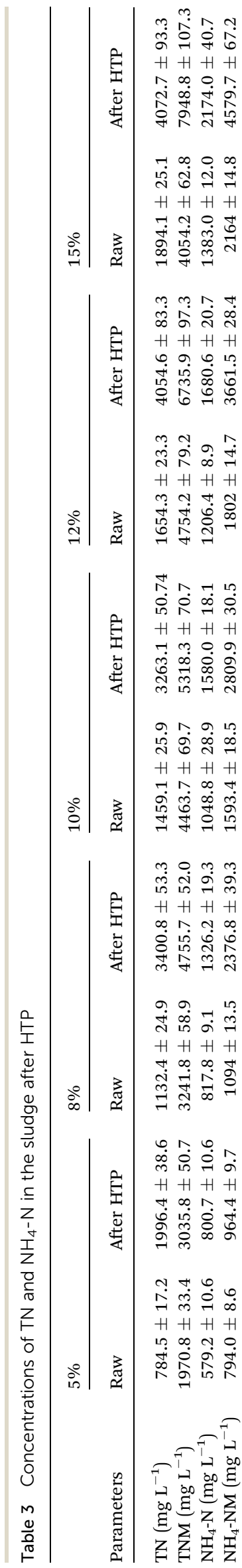




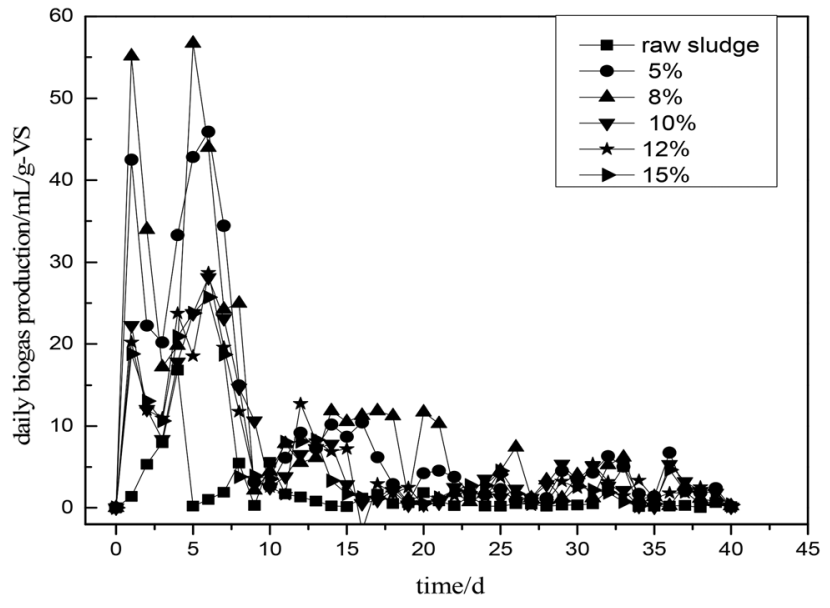

Fig. 3 Change of daily biogas production.

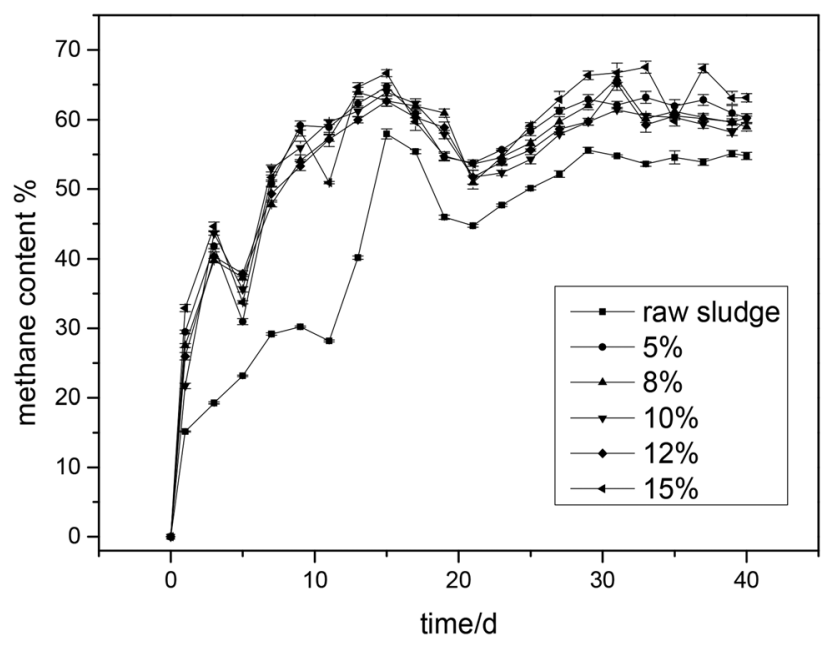

Fig. 4 Variation of methane content.

methane content, which was related to the VFAs production, seen in 3.1.2.

3.2.2 Cumulative biogas yield and T90. HTP led to the physical structure of sludge disrupt, thereby significantly enhanced the solubilization and biodegradation of sludge, improved anaerobic digestion. ${ }^{13}$ Cumulative biogas yield was shown in Fig. 5. Based on the BMP tests, the cumulative biogas yield were $389.31,425.57,238.09,233.20$ and $210.48 \mathrm{~N} \mathrm{ml} \mathrm{g}^{-1}$ VS, for SLR 5\%, 8\%, 10\%, $12 \%$ and $15 \%$, respectively. Compared with the raw sludge ( $66.35 \mathrm{~N} \mathrm{ml} \mathrm{g}^{-1} \mathrm{VS}$ ), the cumulative biogas yield were increased by $486.7 \%, 541.4 \%, 258.8 \%, 251.4 \%$ and $217.2 \%$ for SLR $5 \%, 8 \%, 10 \%, 12 \%$ and $15 \%$, respectively. It indicated that HTP had a positive effect on the biodegradation and hydrolysis of organic matters, led to the enhancement of biogas production. ${ }^{33,53}$ Further more, the cumulative biogas yield increased gradually with the SLR decreased except for the SLR 5\%. It was due to the cumulative biogas yield was corresponded with the solubilization COD, it could be improved as the solubilization COD increased, the tendency was consistent with the 3.1.1. Considering biogas production capacity and

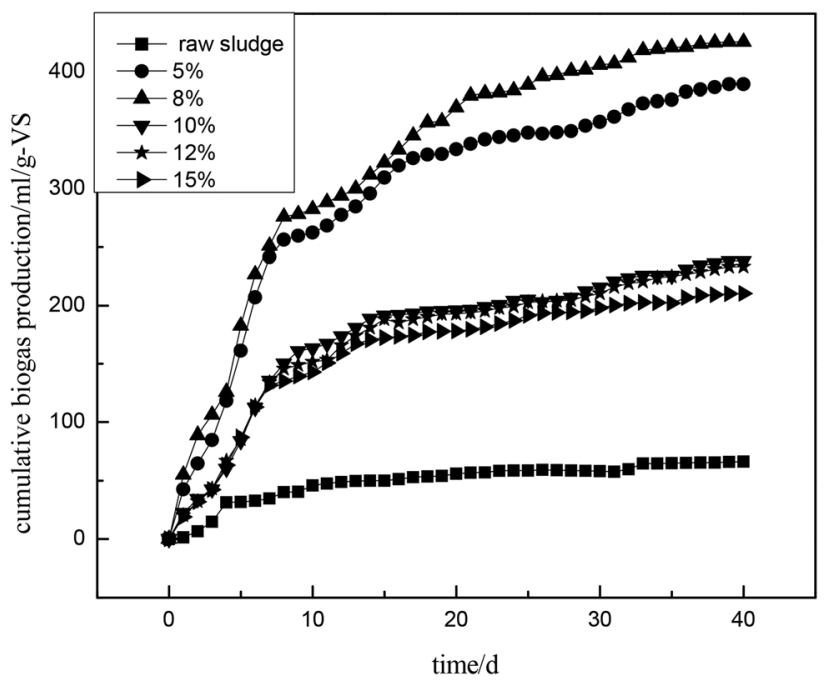

Fig. 5 Variation of cumulative biogas yield.

efficiency, the SLR 8\% was suggested as a preferable condition on anaerobic digestion.

T90 is the time taken for $90 \%$ biogas production, and also is an important index in practical engineering. ${ }^{54}$ The datas were shown in Table 4. After HTP, the T90 were earlier 3, 9, 2, 2, and 7 days for SLR $5 \%, 8 \%, 10 \%, 12 \%$ and $15 \%$, respectively, than the raw sludge, and over $85-90 \%$ of cumulative biogas production was obtained between 20 to 30 days. It can be observed that the SLR 8\% had the lowest T90.

\subsection{Kinetic analysis}

3.3.1 Modified Gompertz model. The cumulative biogas production obtained from BMP tests were fitted with the modified Gompertz model. The kinetic parameters estimated from the modified Gompertz equation were given in Table 5. It could be observed the cumulative biogas production, max biogas potential, max biogas production rate and lag time. The maximum biogas potential were found to be $360.81,403.79$, 217.07, 213.87, 196.52 and $61.66 \mathrm{~N} \mathrm{ml} \mathrm{g}^{-1}$ VS for SLR 5\%, 8\%, $10 \%, 12 \%, 15 \%$ and raw sludge, respectively. The results showed that due to the high biodegradation of the substrate, HTP significantly improved the maximum biogas potential. The SLR $8 \%$ had the highest maximum biogas potential yield because it had the maximum dissolution of organic matter. On the other hand, the lag time was not obvious, the time was

Table 4 T90 of different SLR after HTP

\begin{tabular}{lll}
\hline Parameter & T90 (d) & $\begin{array}{l}\text { 25d cumulative biogas } \\
\text { production }\left(\mathrm{N} \mathrm{ml} \mathrm{g}^{-1} \mathrm{VS}\right)\end{array}$ \\
\hline Raw sludge & 32 & 58.46 \\
SLR 5\% after HTP & 29 & 344.14 \\
SLR 8\% after HTP & 23 & 382.45 \\
SLR 10\% after HTP & 30 & 200.47 \\
SLR 12\% after HTP & 30 & 197.76 \\
SLR 15\% after HTP & 25 & 184.36
\end{tabular}


Table 5 Model parameters of kinetic study

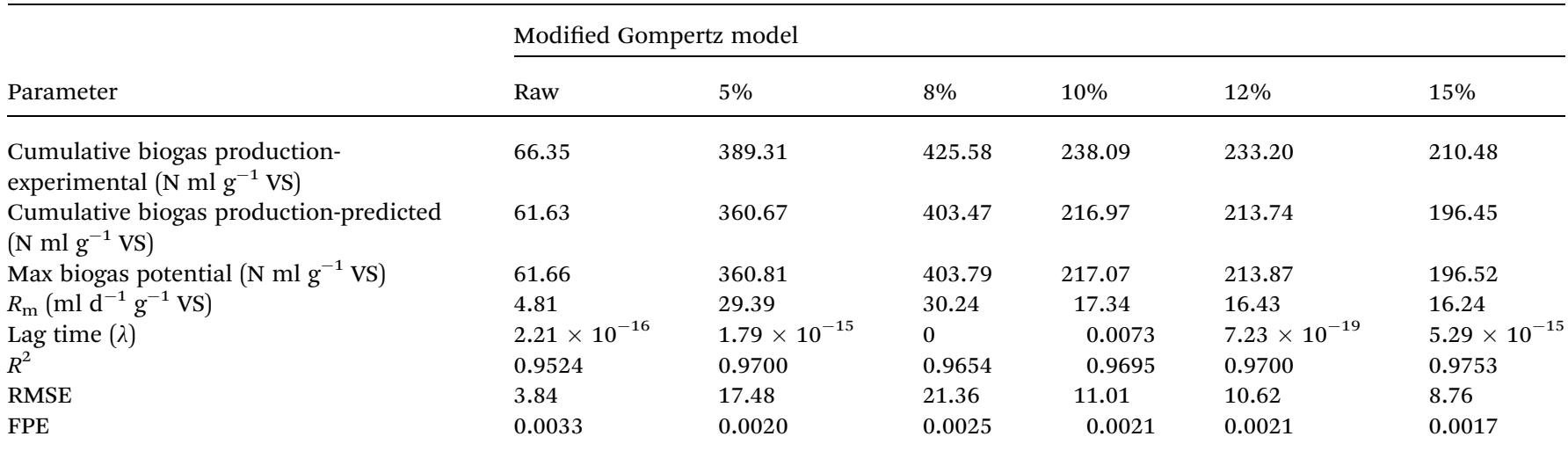

calculated between 0 to 0.0073 days. It indicated that the anaerobic digestion started quickly. Also, the raw sludge had the lowest value of $R^{2}(0.9524)$ and the maximum value of FPE (0.0033). It indicated that the raw sludge had the highest roughness of the cumulative biogas production. While the SLR $15 \%$ had the highest $R^{2}(0.9753)$ and the lowest FPE (0.0017). It revealed that the SLR $15 \%$ had a better fit with the modified Gompertz model.

Fig. 6(a) showed the results of Cumulative biogas production-experimental and modified Gompertz model. The results demonstrated the feasibility of applying the modified Gompertz model to develop the kinetic model of cumulative biogas production due to the high correlation coefficient $\left(R^{2}=\right.$ 0.97524-0.9753), and low FPE (0.0017-0.0033) and RMSE (3.8421.36), indicated a strong linear relationship between the experimental data and the model. Several researchers had used the modified Gompertz model to evaluate the biogas production in the process of anaerobic digestion and had a good fit with the results. Syaichurrozi et al. ${ }^{55}$ researched the kinetic of biogas production and obtained the $R^{2}$ values between 0.958 to 0.969 , and the lag time was between 0.213 to 0.345 days. Cheong et al. ${ }^{56}$ studied the anaerobic hydrogen production of the cattle manure sludge and discussed the kinetic study of the modified Gompertz model, the $R^{2}$ values they obtained were between 0.997 to 1.000 , and the RMSE were between 0.16 to 7.06 .

The comparison between the predicted and experimental cumulative biogas production values for the six samples were shown in Fig. 6(b). It showed that the $R^{2}$ value was obtained as 0.9662 when used the modified Gompertz model. The overall percentage deviation for the six samples was $+26.7 \%$. The results indicated that the experimental data could be fitted with the modified Gompertz model and could used the model to determine the cumulative biogas production, max biogas potential, maximum biogas production rate and lag time.

3.3.2 Logistic model. Table 6 showed the kinetic parameters calculated from the Logistic equation. The lag time was between $1.20 \times 10^{-15}$ to 4.65 days, which was higher than the results of the modified Gompertz model. The correlation coefficient $\left(R^{2}\right)$ values for the six samples (SLR $5 \%, 8 \%, 10 \%, 12 \%$, $15 \%$ and raw sludge) were $0.9533,0.9461,0.9571,0.9548,0.9607$ and 0.9297 , respectively. The correlation coefficient $\left(R^{2}\right)$ values showed that the experimental results could be fitted with the
Logistic model. And the SLR $15 \%$ had the highest $R^{2}(0.9607)$, but the raw sludge had the lowest $R^{2}(0.9297)$. This results were similar with the modified Gompertz model. Adjusting the SLR

(a)

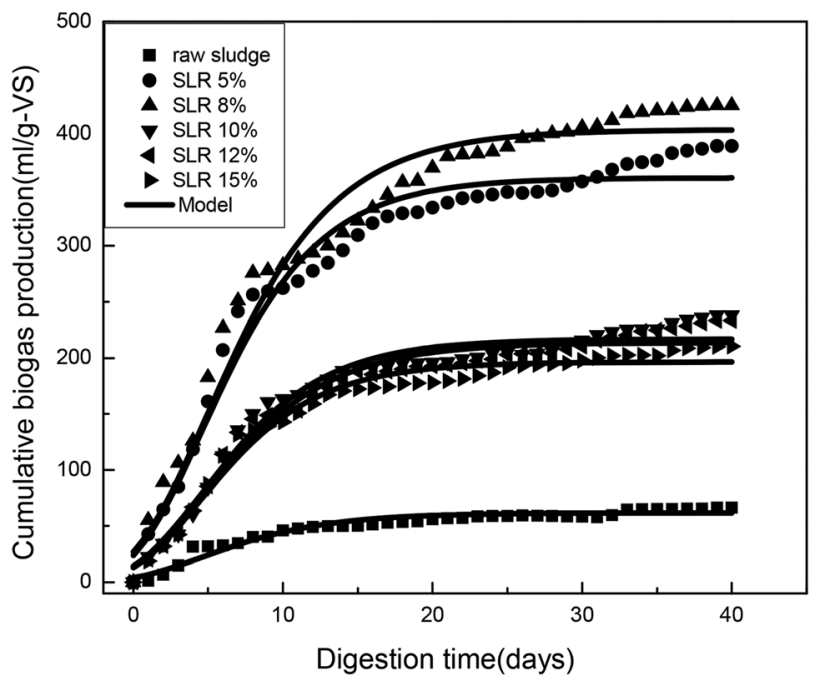

(b)

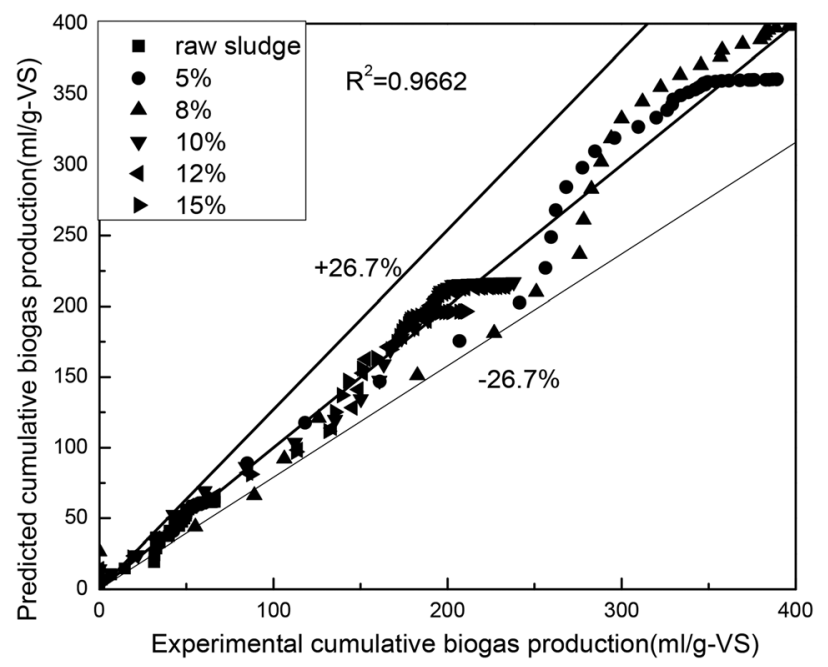

Fig. 6 (a) Cumulative biogas production-experimental and modified Gompertz model. (b) Comparison between experimental and predicted (modified Gompertz model) cumulative biogas production. 
Table 6 Model parameters of kinetic study

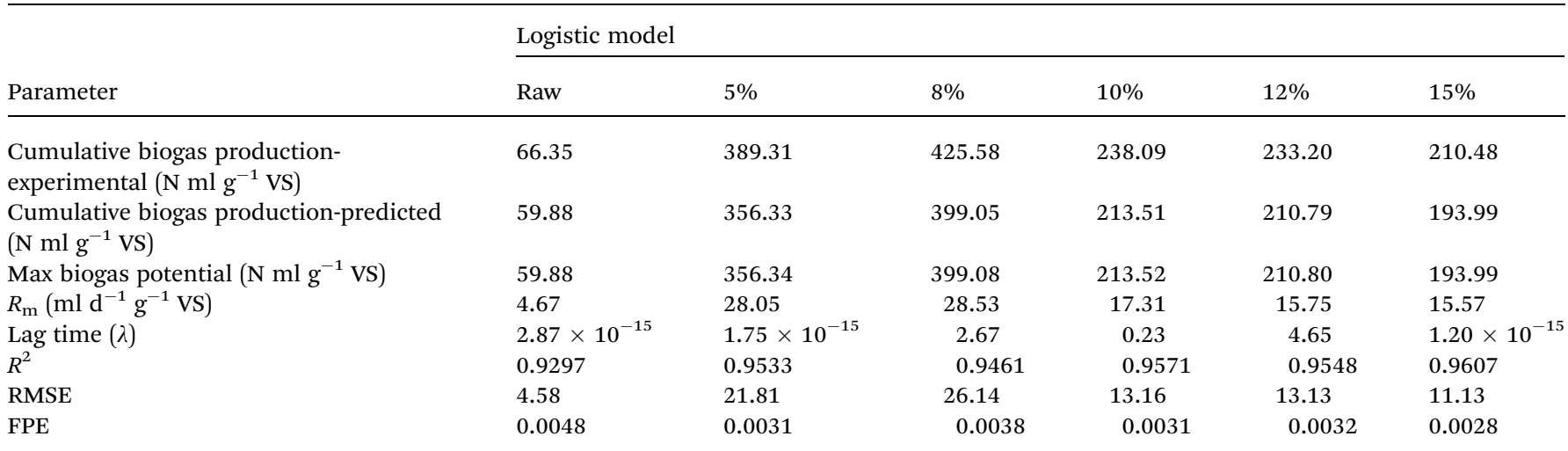

of sludge was benefit to improve the cumulative biogas production. Also, the raw sludge had the highest value of FPE (0.0048) and the SLR 15\% had the lowest value of FPE (0.0028).

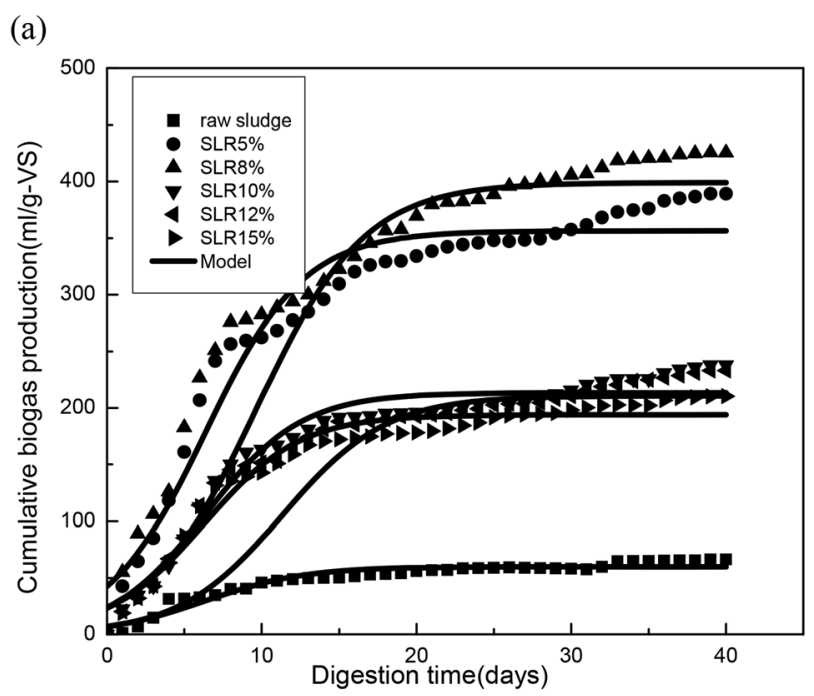

(b)

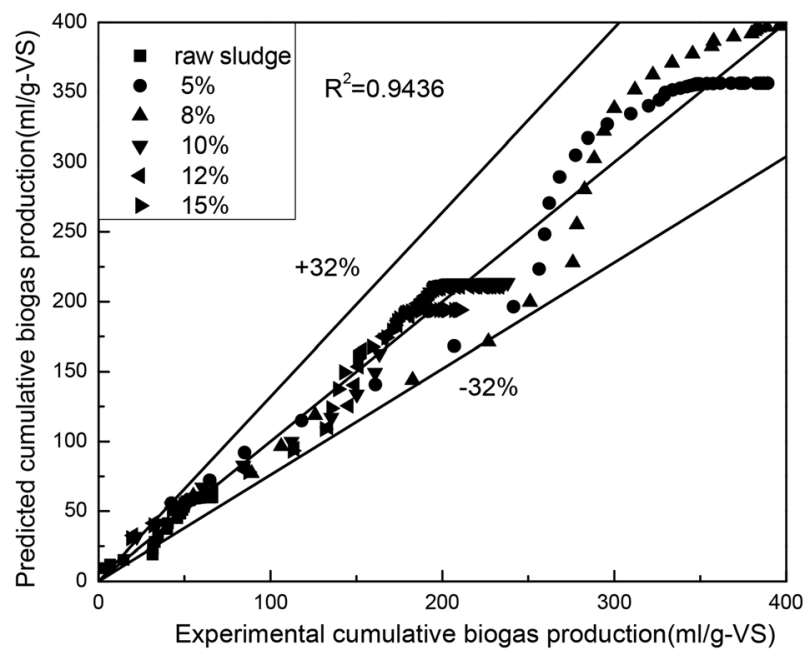

Fig. 7 (a) Cumulative biogas production-experimental and Logistic model. (b) Comparison between experimental and predicted (Logistic model) cumulative biogas production.
Therefore, the Logistic model could accurately reflected the cumulative biogas production of anaerobic digestion, and the SLR $15 \%$ had a better fit with the Logistic model. The fitted curves for Logistic model were shown in Fig. 7(a), it evaluated the model results for the Logistic model, there were not much difference of the cumulative biogas production between the experimental values and model datas.

Fig. 7(a) showed the comparison of predicted and experimental cumulative biogas production values for the six samples. The $R^{2}$ value was obtained as 0.9436 when used the Logistic model. The overall percentage deviation for the six samples was $+32 \%$. This showed that the experimental data could be fitted with the Logistic model for kinetic study and the Logistic model could determined the cumulative biogas production, max biogas potential, max biogas production rate and lag time accurately.

It could be observed that the correlation coefficient $\left(R^{2}\right)$ values of the Logistic model were lower than the modified Gompertz model. Root mean square error (RMSE), Final Prediction Error (FPE) and overall percentage deviation of the Logistic model were higher than the modified Gompertz model. This indicated that the modified Gompertz model fitted well for the kinetic study of anaerobic digestion process. So the modified Gompertz model was more suitable for the evaluation of anaerobic digestion kinetic study.

\section{Conclusions}

In this study, the solubilization $\mathrm{COD}, \mathrm{NH}_{4}-\mathrm{N}$, VFAs, biogas production for the different SLR between the raw sludge and after HTP were analysed. HTP had promoting effect on anaerobic digestion, which increased the solubilization of organic matter. However, the different SLR had an important influence on anaerobic digestion. The results showed that the SLR 8\% was conducive to the solubilization of COD, also had the highest cumulative biogas yield and methane content. The solubilization COD reached at $96.09 \%$, the cumulative biogas yield was $425.57 \mathrm{~N} \mathrm{ml} \mathrm{g}^{-1} \mathrm{VS}$, and the methane content reached on $67 \%$. Therefore, controlling the SLR of sludge in the suitable range would benefit to the dissolution of organic matter. It could not only saved the cost of sludge treatment, but also improved the methane content. The modified Gompertz model and Logistic 
model were used to evaluate the performance of anaerobic digestion, and two models had a good fit. The higher values of the $R^{2}$ were between 0.97524 to 0.975 , the lower values of the FPE were between 0.0017 to 0.0033 and the RMSE were between 3.84 to 21.36. It demonstrated that the modified Gompertz model was better fitted with the experimental datas than the Logistic model. Finally, the methane production at suitable range of SLR increased significantly, which provided the basis for the industrial application.

\section{Conflicts of interest}

There are no conflicts to declare.

\section{Acknowledgements}

This research was supported in part by "Study on Recycling Technology of C, N, P in Surplus Sludge of Sewage Treatment Plant" of the Key Research and Development Plan in ShanDong Province (No. 2017GSF16108). This study also partially supported by "Research on water intrusion repair technology based on water sensitivity" of the Shandong Provincial Natural Science Foundation (No. ZR2017LD007) and the Key Technologies Research and Development Program of Shandong Province, China (No. 2018GSF117016).

\section{References}

1 A. Demirbas, Progress and recent trends in biofuels, Prog. Energy Combust. Sci., 2007, 33(1), 1-18.

2 D. Özçimen and F. Karaosmanoğlu, Production and characterization of bio-oil and biochar from rapeseed cake, Renewable Energy, 2004, 29, 779-787.

3 M. Jefferson, Sustainable energy development: performance and prospects, Renewable Energy, 2006, 31(5), 571-582.

4 P. Neumann, A. Torres, F. G. Fermoso, et al., Anaerobic codigestion of lipid-spent microalgae with waste activated sludge and glycerol in batch mode, Int. Biodeterior. Biodegrad., 2015, 100, 85-88.

5 C. Ratanatamskul, G. Onnum and K. Yamamoto, A prototype single-stage anaerobic digester for co-digestion of food waste and sewage sludge from high-rise building for on-site biogas production, Int. Biodeterior. Biodegrad., 2014, 95, 176-180.

6 S. Ghosh, J. R. Conrad and D. L. Klass, Anaerobic acidogenesis of wastewater sludge, J. - Water Pollut. Control Fed., 1975, 47(1), 30-45.

7 L. D. Nghiem, T. T. Nguyen, P. Manassa, et al., Co-digestion of sewage sludge and crude glycerol for on-demand biogas production, Int. Biodeterior. Biodegrad., 2014, 95, 160-166.

8 V. K. Tyagi and S. L. Lo, Sludge: a waste or renewable source for energy and resource recovery?, Renewable Sustainable Energy Rev., 2013, 25, 708-728.

9 P. Weiland, Biogas production: current state and perspectives, Appl. Microbiol. Biotechnol., 2010, 85(4), 849860.
10 S. Kumar, S. Mukherjee and S. Devotta, Anaerobic digestion of vegetable market waste in India, World Review of Science Technology \& Sustainable Development, 2010, 7(3), 217-224.

11 A. M. Yeneneh, S. Chong, T. K. Sen, et al., Effect of ultrasonic, microwave and combined microwave-ultrasonic pretreatment of municipal sludge on anaerobic digester performance, Water, Air, Soil Pollut., 2013, 224(5), 1-9.

12 C. Bougrier, J. P. Delgenes and H. Carrere, Effects of thermal treatments on five different waste activated sludge samples solubilisation, physical properties and anaerobic digestion, Chem. Eng. J., 2008, 139(2), 236-244.

13 J. Ariunbaatar, A. Panico, G. Esposito, et al., Pretreatment methods to enhance anaerobic digestion of organic solid waste, Appl. Energy, 2014, 123, 143-156.

14 E. A. Ehimen, J. B. Holm-Nielsen, M. Poulsen, et al., Influence of different pretreatment routes on the anaerobic digestion of a filamentous algae, Renewable Energy, 2013, 50(3), 476-480.

15 R. U. Rani, S. A. Kumar, S. Kaliappan, et al., Impacts of microwave pretreatments on the semi-continuous anaerobic digestion of dairy waste activated sludge, Waste Manage., 2013, 33(5), 1119-1127.

16 K. Lee, P. Chantrasakdakul, D. Kim, et al., Ultrasound pretreatment of filamentous algal biomass for enhanced biogas production, Waste Manage., 2014, 34(6), 1035-1040.

17 T. Gayathri, S. Kavitha, S. Adish Kumar, et al., Effect of citric acid induced deflocculation on the ultrasonic pretreatment efficiency of dairy waste activated sludge, Ultrason. Sonochem., 2015, 22, 333-340.

$18 \mathrm{M}$. Takashima and Y. Tanaka, Acidic thermal post-treatment for enhancing anaerobic digestion of sewage sludge, $J$. Environ. Chem. Eng., 2014, 2(2), 773-779.

19 I. T. Yeom, K. R. Lee, K. H. Ahn, et al., Effects of ozone treatment on the biodegradability of sludge from municipal wastewater treatment plants, Water Sci. Technol., 2002, 46(4-5), 421-425.

20 H. Carrère, C. Dumas, A. Battimelli, et al., Pretreatment methods to improve sludge anaerobic degradability: a review, J. Hazard. Mater., 2010, 183(1-3), 1-15.

21 F. Passos and I. Ferrer, Microalgae conversion to biogas: thermal pre-treatment contribution on net energy production, Environ. Sci. Technol., 2014, 48(12), 7171-7178.

22 D. Kim, K. Lee and K. Y. Park, Hydrothermal carbonization of anaerobically digested sludge for solid fuel production and energy recovery, Fuel, 2014, 130, 120-125.

23 S. Calligaris, F. Valoppi, L. Barba, et al., $\beta$-Carotene degradation kinetics as affected by fat crystal network and solid/liquid ratio, Food Res. Int., 2018, 105, 599-604.

24 M. Escala, T. Zumbuhl, C. Koller, et al., Hydrothermal carbonization as an energy-efficient alternative to established drying technologies for sewage sludge: a feasibility study on a laboratory scale, Energy Fuels, 2013, 27(1), 454-460.

25 F. Passos and I. Ferrer, Influence of hydrothermal pretreatment on microalgal biomass anaerobic digestion and bioenergy production, Water Res., 2015, 68, 364-373. 
26 G. H. Feng, L. Y. Liu and W. Tan, Effect of thermal hydrolysis on rheological behavior of municipal sludge, Ind Eng. Chem. Res., 2014, 53(27), 11185-11192.

27 J. Zhang, S. Wang, S. Lang, et al., Kinetics of combined thermal pretreatment and anaerobic digestion of waste activated sludge from sugar and pulp industry, Chem. Eng. J., 2016, 295, 131-138.

28 M. T. Reza, J. Andert, B. Wirth, et al., Hydrothermal carbonization of biomass for energy and crop production, Applied Bioenergy, 2014, 1, 11-28.

29 Z. Wang, T. Jia, J. Wang and L. Gong, Effect of hydrothermal pretreatment on physical and chemical properties of sludge, J. Environ. Eng. Technol., 2016, 6(05), 440-446.

30 G. Liu, R. Zhang, H. M. Elmashad, et al., Effect of feed to inoculum ratios on biogas yield of food and green wastes, Bioresour. Technol., 2009, 100(1), 5103-5108.

31 F. Raposoa, R. Borjaa, M. A. Martín, A. Martin, et al., Influence of inoculum-substrate ratio on the anaerobic digestion of sunflower oil cake in batch mode: process stability and kinetic evaluation, Chem. Eng. J., 2009, 149, 70-77.

32 D. Kim, K. Lee and K. Y. Park, Enhancement of biogas production from anaerobic digestion of waste activated sludge by hydrothermal pre-treatment, Int. Biodeterior. Biodegrad., 2015, 101, 42-46.

33 A. G. Vlyssides and P. K. Karlis, Thermal-alkaline soubilization of waste activated sludge as a pre-treatment stage for anaerobic digestion, Bioresour. Technol., 2004, 91, 201-206.

34 S. Pommier, D. Chenu, M. Quintard and X. Lefebvre, A logistic model for the prediction of the influence of water on solid waste methanization in landfills, Biotechnol. Bioeng., 2007, 97, 473-474.

35 A. Nopharatana, P. C. Pullammanappallil and W. P. Clarke, Kinetics and dynamic modelling of batch anaerobic digestion of municipal solid waste in a stirred reactor, Waste Manag., 2006, 27, 595-603.

36 G. K. Kafle, H. K. Sang and K. I. Sung, Ensiling of fish industry waste for biogas production: a lab scale evaluation of biochemical methane potential (BMP) and kinetics, Bioresour. Technol., 2012, 127(1), 326-336.

37 D. Pham Van, et al., Kinetics of carbon dioxide, methane and hydrolysis in co-digestion of food and vegetable wastes, Global J. Environ. Sci. Manage., 2018a, 401-412.

38 D. Pham Van, G. Hoang Minh, S. T. Pham Phu and T. Fujiwara, A new kinetic model for biogas production from co-digestion by batch mode, Global J. Environ. Sci. Manage., 2018b, 4(3), 251-262.

39 Y. Kurtgoz, M. Karagoz and E. Deniz, Biogas engine performance estimation using ANN, Engineering Science and Technology, an International Journal, 2018, 20, 15631570.

40 J. L. Urrea, M. García, S. Collado, et al., Sludge hydrothermal treatments. Oxidising atmosphere effects on biopolymers and physical properties, J. Environ. Manage., 2017, 206, 284.

41 Y. J. Seong, W. C. Soon, et al., Influence of thermal hydrolysis pretreatment on physicochemical properties and anaerobic biodegradability of waste activated sludge with different solids content, Waste Manage., 2019, 85, 214-221.

42 F. Markis, J. C. Baudez, R. Parthasarathy, P. Slatter and N. Eshtiaghi, Predicting the apparent viscosity and yield stress of mixtures of primary, secondary and anaerobically digested sewage sludge: simulating anaerobic digesters, Water Res., 2016, 100, 568-579.

43 S. Park, Y. M. Yoon, S. K. Han, et al., Effect of hydrothermal pre-treatment (HTP) on poultry slaughterhouse waste (PSW) sludge for the enhancement of the solubilization, physical properties, and biogas production through anaerobic digestion, Waste Manage., 2017, 64, 327-332.

44 L. Zhang, X. He, et al., Evaluating the influences of $\mathrm{ZnO}$ engineering nanomaterials on VFA accumulation in sludge anaerobic digestion, Biochem. Eng. J., 2017, 125, 206-211.

45 C. A. Wilson and J. T. Novak, Hydrolysis of macromolecular components of primary and secondary wastewater sludge by thermal hydrolytic pretreatment, Water Res., 2009, 43(18), 4489-4498.

46 Y. Li, Y. Jin, J. Li, et al., Effects of thermal pretreatment on degradation kinetics of organics during kitchen waste anaerobic digestion, Energy, 2017, 118, 377-386.

47 S. Sung and T. Liu, Ammonia inhibition on thermophilic anaerobic digestion, Chemosphere, 2003, 53(1), 43-52.

48 Y. Jin, Y. Li and J. Li, Influence of thermal pretreatment on physical and chemical properties of kitchen waste and the efficiency of anaerobic digestion, J. Environ. Manage., 2016, 180, 291-300.

49 C. Rong, K. Yasuhiro and N. Toshiyuki, Enhancement of methane production by, Methanosarcina barkeri, using $\mathrm{Fe}_{3} \mathrm{O}_{4}$, nanoparticles as iron sustained release agent, Adv. Powder Technol., 2018, 29, 2429-2433.

50 N. Eshtiaghi, F. Markis, D. Zain, et al., Predicting the apparent viscosity and yields stress of digested and secondary sludge mixtures, Water Res., 2016, 95, 159-164.

51 M. Herout, J. Malatak, L. Kucera and T. Dlabaja, Biogas composition depending on the type of plant biomass used, Res. Agric. Eng., 2011, 57(4), 137-143.

52 T. Seviour, M. Pijuan, T. Nicholson, et al., Gel-forming exopolysaccharides explain basic differences between structures of aerobic sludge granules and floccular sludges, Water Res., 2009, 43(18), 4469-4478.

53 Y. Li, S. Y. Park and J. Zhu, Solid-state anaerobic digestion for methane production from organic waste, Renewable Sustainable Energy Rev., 2011, 15(1), 821-826.

54 M. J. Kim and S. H. Kim, Minimization of diauxic growth lagphase for high-efficiency biogas production, J. Environ. Manage., 2016, 187, 456-463.

55 I. Syaichurrozi, Budiyono and S. Sumardiono, Predicting kinetic model of biogas production and biodegradability organic materials: biogas production from vinasse at variation of $\mathrm{COD} / \mathrm{N}$ ratio, Bioresour. Technol., 2013, 149, 390-397.

56 D. Y. Cheong and C. L. Hansen, Bacterial stress enrichment enhances anaerobic hydrogen production in cattle manure sludge, Appl. Microbiol. Biotechnol., 2006, 72(4), 635-643. 